\title{
Successful maternal and fetal outcome in a case of BOH with APLA positive status
}

\author{
Annal Vaidya*, Kimaya Mali, Meena Satia
}

Department of Obstetrics and Gynecology, G. S. Medical College and King Edward Memorial Hospital, Mumbai, Maharashtra, India

Received: 18 July 2017

Accepted: 18 August 2017

\section{*Correspondence:}

Dr. Annal Vaidya,

E-mail: annalvaidya911@gmail.com

Copyright: (c) the author(s), publisher and licensee Medip Academy. This is an open-access article distributed under the terms of the Creative Commons Attribution Non-Commercial License, which permits unrestricted non-commercial use, distribution, and reproduction in any medium, provided the original work is properly cited.

\begin{abstract}
The Antiphospholipid antibody syndrome is an autoimmune disorder that occurs when body's immune system makes antibodies that attack and damage the tissues. These antibodies that mistakenly attack phospholipids found in the lining of the blood vessels result in formation of clots. The effect of thrombophilia on pregnancy is uncertain. Here we discuss a case of preterm abruption at 30 weeks of gestation in a patient with Lupus positive status in a patient without preeclampsia.
\end{abstract}

Keywords: Abruption, Low molecular weight heparin, Lupus anticoagulant

\section{INTRODUCTION}

Antiphospholipid syndrome is a condition in which there is increased tendency of formation of abnormal blood clots which results in blockage of blood vessels. This abnormal clotting capability is known as thrombophilia.

There is definite association of thrombophilia with preeclampsia, placental abruption, severe intrauterine growth restriction or fetal demise. ${ }^{1-4}$ In antiphospholipid syndrome, there can be formation of blood clots in nearly any blood vessel. Antiphospholipid syndrome affects women five times more commonly than men. It is typically diagnosed between the ages of 30 and 40 years. While up to $40 \%$ of patients with SLE test positive for the anti-phospholipid autoantibodies, only half develop thrombosis and/or experience miscarriages. The coexistence of thrombophilia with abruption placentae shows greater evidence of placental infarcts and necrosed areas within the decidua. ${ }^{5,6}$ These lesions justify the presence of placental abruption in cases with maternal thrombophilias.

\section{CASE REPORT}

27-year-old patient a case of $\mathrm{BOH}$ with $3^{\text {rd }}$ degree consanguineous marriage with previous 2 FTND followed by neonatal deaths within 10 minutes after birth, presented in ANC OPD for registration. In view of $\mathrm{BOH}$ patient was admitted at 18 weeks gestation for thorough evaluation and investigations. Maternal and Paternal karyotyping was done to rule out translocation and was found to be normal. Lupus anticoagulant was positive. ACLA, ANA, Anti ds-DNA and Beta 2 Glycoprotein were all negative.

Her haematology reference was done in view of LA positive status with Dilute Russel Viper venom test (DRVT) time of 48.6 seconds on a control of 32.8 seconds. She was advised to take Tablet Aspirin $75 \mathrm{mg}$ OD and Injection Low molecular weight Heparin 
throughout pregnancy and was advised to continue it for 6weeks post-partum. Also, she was advised to increase dose of Heparin if there was increased resistance in umbilical artery on feto-maternal Doppler study.

At 30 weeks of gestation she came to emergency department with complaints of bleeding per vaginum. On clinical examination, there was no evidence of preeclampsia, a clinical diagnosis of antepartum haemorrhage was made and ultrasonography was advised. On sonography placenta was found to be fundal and on anterior wall and there was no sign of placental separation as well. Patient was treated in ANC ward as a case of threatened preterm labour and she responded to tocolysis. All routine investigations were normal. Patient was given conservative line of management and was advised strict bed rest. 2 doses of injection Betamethasone $12 \mathrm{mg}$ were given intramuscular 24 hours apart. Her complaints of spotting per vaginum reduced within 3 days, after that patient was discharged on her persistent request. One-week later patient again presented with bleeding per vaginum. Her general condition was good and per abdominal examination revealed tonically contracted uterus and a clinical diagnosis of abruption placentae was made and sonography was done which showed a retro-placental clot of 300-400 grams. An emergency lower segment caesarean section was done. The patient withstood the procedure well and baby was shifted to NICU. Initially, the baby was put on CPAP and IV fluids and IV antibiotics were started. Eventually, the baby maintained $\mathrm{O} 2$ saturation on room air and tolerated partial feeds well. There was adequate weight gain within a period of 3 weeks as the baby tolerated full feeds subsequently.

\section{DISCUSSION}

Thrombotic disease is one of the important cause of peripartum morbidity and mortality in the world. The cause of thrombosis in pregnancy is multifactorial due to the hypercoagulable state which is a physiologic change of pregnancy. Venous thromboembolism is seen in antiphospholipid antibody syndrome which is the main cause of acquired thrombophilias. The following criteria must be fulfilled for the diagnosis of antiphospholipid antibody syndrome. These diagnostic criteria should suggest $\mathrm{H} / \mathrm{O}$ one or more episodes of documented thrombosis, and/or poor pregnancy outcome, preterm delivery at $\leq 34$ weeks or preeclampsia or utero-placental insufficiency. Two tests for Lupus anticoagulant should be done at the interval of 12 weeks and they should be positive on 2 separate occasions and/or anti-cardiolipin antibody should be present with high titres $>40$ of either the IgG or IgM isotype, or the anti-beta2-glycoprotein should be positive of $\operatorname{IgG}$ or $\operatorname{IgM}$ isotype on 2 or more testing sessions with a gap of atleast 12 weeks. $^{7}$

Placental abruption has been identified as being part of the spectrum of ischemic placental disease and is postulated to be a chronic disease process. Maternal thrombophilia predisposes women to placental abruption by causing chronic utero-placental insufficiency rather than an acute disruption of the feto-maternal interface although a consistent association has not been established. During pregnancy the increased risk of thrombosis in these patients can be quite substantial and needs consideration. Patients with underlying thrombophilia may show thrombosis during pregnancy in almost $50 \%$ of cases. In addition to acquired thrombophilias giving rise to abruption various studies have suggested that hyperhomocystinemia may also be associated with placental abruption. ${ }^{8,9}$ Besides an increased risk of thromboembolic events, an association of hereditary Factor V Leiden mutation with impaired early trophoblast invasion early in gestation, eventually leads to preeclampsia, fetal growth retardation and other complications of pregnancy. In normal coagulation cascade, coagulation factor $\mathrm{V}$ forms a complex with activated factor $\mathrm{X}$, phospholipids and Calcium ions, which transduces prothrombin into thrombin. A point mutation i.e. G1691A within the factor $\mathrm{V}$ gene the socalled factor $\mathrm{V}$ Leiden leads to resistance to activated protein $\mathrm{C}$ i.e. APC-resistance

Anticoagulant of choice during pregnancy is low molecular weight heparin although adjusted-dose unfractionated heparin (UHF) can also be used. Multiple advantages of LMWH like longer half-life, less number of injections required, less incidence of osteoporosis and good bioavailability have made it more preferred choice in comparison to unfractionated heparin. Low molecular weight heparin is initiated as early as possible in pregnancy and at the $36^{\text {th }}$ week of pregnancy one needs to switch to unfractionated heparin in order to avoid complications of epidural anaesthesia that can occur with the longer half-life of low molecular weight heparins. In the postpartum period, either continuation of low molecular weight heparin or switching over to warfarin after overlapping is acceptable.

\section{CONCLUSION}

Our case shows that there is a strong correlation between the thrombophilia and pregnancy complications, most commonly abruption. The women with $\mathrm{BOH}$ should be thoroughly investigated and pregnancy should be carefully monitored.

\section{Funding: No funding sources \\ Conflict of interest: None declared \\ Ethical approval: Not required}

\section{REFERENCES}

1. Moldenhauer JS, Stanek J, Warshak C, Khoury J, Sibai B. The frequency and severity of placental findings in women with preeclampsia are gestational age dependent. Am J Obstet Gynecol. 2003;189:1173-7. 
2. Sugimura M, Ohashi R, Kobayashi T, Kanayama N. Intraplacental coagulation in intrauterine growth restriction: cause or result? Semin Thromb Hemost. 2001;27:107 -13.

3. Salafia CM, Lopez-Zeno JA, Sherer DM, Whittington SS, Minior VK, Vintzileos AM. Histologic evidence of old intrauterine bleeding is more frequent in prematurity. Am J Obstet Gynecol. 1995;173:1065-70.

4. Salafia CM, Pezzullo JC, Ghidini A, Lopez-Zeno JA, Whittington SS. Clinical correlations of patterns of placental pathology in preterm pre-eclampsia. Placenta. 1998;19:67-72.

5. Wiener-Megnagi Z, Ben-Shlomo I, Goldberg Y, Shalev E. Resistance to activated protein $C$ and the Leiden mutation: high prevalence in patients with abruptio placentae. Am J Obstet Gynecol. 1998;179:1565-7.

6. Robertson L, Wu O, Langhorne P. Thrombophilia in pregnancy: a systematic review. Br J Haematol. 2006;132:171-96.
7. Miyakis S, Lockshin MD, Atsumi T. "International consensus statement on an update of the classi cation criteria for de nite antiphospholipid syndrome (APS)," Journal of Trombosis and Haemostasis. 2006;4(2):295-306.

8. Al revic $\mathrm{Z}$, Roberts $\mathrm{D}$, and Martlew $\mathrm{V}$, "How strong is the association between maternal thrombophilia and adverse pregnancy outcome? A systematic review," European J Obstetrs Gynecol Reproduct Biol. 2002;101(1):6-14.

9. Ray JG, Laskin CA, "Folic acid and homocyst (e) ine metabolic defects and the risk of placental abruption, pre-eclampsia and spontaneous pregnancy loss: a systematic review," Placenta. 1999;20(7):519-29.

Cite this article as: Vaidya A, Mali K, Satia M. Successful maternal and fetal outcome in a case of $\mathrm{BOH}$ with APLA positive status. Int J Reprod Contracept Obstet Gynecol 2017;6:4708-10. 